BALDISSERA, Rafaela. AQUINO. Sérgio Ricardo Fernandes de. A ilusória tutela penal de um meio ambiente sustentável. Revista Eletrônica Direito e Política, Programa de Pós-Graduação Stricto Sensu em Ciência Jurídica da UNIVALI, Itajaí, v.11, n.2, 2ㅇ quadrimestre de 2016. Disponível em: www.univali.br/direitoepolitica - ISSN 1980-7791.

\title{
A ILUSÓRIA TUTELA PENAL DE UM MEIO AMBIENTE SUSTENTÁVEL
}

THE ILLUSORY CRIMINAL TUTELAGE OF THE SUSTAINABLE ENVIRONMENT

Rafaela Baldissera ${ }^{1}$ Sérgio Ricardo Fernandes de Aquino² Diogo Dal Magro3

SUMÁRIO: Introdução. 1. A sustentabilidade e a crise ambiental; 2. Meio ambiente: um bem juridicamente protegido; 3. A deslegitimação do direito penal frente à tutela do meio ambiente; Considerações finais; Referências das fontes citadas

RESUMO: Apesar de discursos declarados tentarem validar o sistema penal com reparador e inibidor de danos ambientais, percebe-se que, na prática, as promessas, com viés ambiental protetivo, estão longe de serem satisfeitas. Diante desse cenário, utilizando-se do método dedutivo, este estudo tem o objetivo de investigar se o direito penal pode ser considerado um sistema coerente para garantir a tutela do

1 Mestranda em Direito pela Faculdade Meridional (IMED), linha de pesquisa
"Mecanismos de Efetivação da Democracia e da Sustentabilidade". Especialista em
Direito Processual Civil e Direito do Trabalho e Processo do Trabalho pela Faculdade
Meridional (IMED). Especialista em Direito Notarial e Registral, Direito Previdenciário,
Direito Civil e Direito Empresarial e Advocacia Empresarial pela Universidade
Anhanguera Uniderp. Pesquisadora do Grupo de Pesquisa: Multiculturalismo e
Pluralismo Jurídico. Membro do Grupo de Pesquisa: Ética, Cidadania e
Sustentabilidade. Advogada. Passo Fundo/RS. Brasil. E-mail: rafaela_baldissera@hotmail.com.

2 Doutor e Mestre em Ciência Jurídica pela Universidade do Vale do Itajaí - UNIVALI. Professor Permanente do Programa de Pós-Graduação Stricto Sensu - Mestrado em Direito do Complexo de Ensino Superior Meridional - IMED. Professor do Curso de Direito da Faculdade Meridional - IMED. Pesquisador da Faculdade Meridional. Coordenador do Grupo de Pesquisa: Ética, Cidadania e Sustentabilidade. Membro do Grupo de Pesquisa: "Modernidade, Pós-Modernidade e Pensamento Complexo", "Multiculturalismo e Pluralismo Jurídico" e "Transnacionalismo e circulação de modelos jurídicos". Membro associado do Conselho Nacional de Pós-Graduação em Direito - CONPEDI e da Associação Brasileira do Ensino de Direito - ABEDI. Passo Fundo. RS. Brasil. E-mail: sergiorfaquino@gmail.com ou sergio.aquino@imed.edu.br. 3 Acadêmico do 30 período do Curso de Direito da Faculdade Meridional - Imed. Membro do Grupo de Pesquisa "Ética, Cidadania e Sustentabilidade". E-mail: diogo.dalmagro@yahoo.com.br. 

Sensu em Ciência Jurídica da UNIVALI, Itajaí, v.11, n.2, 2ㅇ quadrimestre de 2016. Disponível em: www.univali.br/direitoepolitica - ISSN 1980-7791.

meio ambiente, contribuindo para a concretização da sustentabilidade ambiental. Nesse sentido, com a análise da crise ambiental e da sustentabilidade, bem como da proteção jurídica do meio ambiente e a deslegitimação do direito penal frente à tutela ambiental, pode-se concluir que o direito penal traz uma falsa ideia de tutela ambiental, pois não é um sistema adequado para proteger o meio ambiente, muito menos para promover a sustentabilidade.

PALAVRAS-ChAVE: Meio Ambiente. Direito Penal. Sustentabilidade.

ABSTRACT: Although declared speeches try to validate the penal system as a repairer and inhibitor of environmental damage, it is clear that in practice the promises, with protective bias, are far from being met. Therefore, using the deductive method and technical literature, this study aims to investigate whether the criminal law can be considered a coherent system to ensure the protection of the environment, contributing to the achievement of environmental sustainability. In this sense, the analysis of the environmental crisis and sustainability, as well as the legal protection of the environment and the delegitimization of the criminal front right to environmental protection, it can be concluded that criminal law provides a false idea of environmental protection, because no it is an adequate system to protect the environment, much less to promote sustainability.

KEYWORDS: Environment. Criminal Law. Sustainability.

\section{INTRODUÇÃO}

Em meio às crises ecológicas, as primeiras ideias de sustentabilidade foram divulgadas em legislações europeias, ainda no século XIV, quando graves problemas ambientais foram constatados e foi apresentada a excessiva extração dos meios naturais como a principal causa destes desequilíbrios.

Dessa forma, compreende-se que, há séculos, a União Europeia já havia solicitado que a sua população ponderasse a utilização dos recursos da natureza, aguardando sua inteira recomposição para, somente após, empregá-los novamente. Entretanto, a crise ambiental 
BALDISSERA, Rafaela. AQUINO. Sérgio Ricardo Fernandes de. A ilusória tutela penal de um meio ambiente sustentável. Revista Eletrônica Direito e Política, Programa de Pós-Graduação Stricto Sensu em Ciência Jurídica da UNIVALI, Itajaí, v.11, n.2, 2ำ quadrimestre de 2016. Disponível em: www.univali.br/direitoepolitica - ISSN 1980-7791.

se alastrou atingindo outras localidades do mundo, assim novas atitudes humanas foram necessárias para minimizar seus efeitos e, entre elas, destacam-se os movimentos ambientalistas, as conferências com viés ecológico, os documentos favoráveis ao meio ambiente e, inclusive, comissões mundiais voltadas a encontrar o equilíbrio dos sistemas naturais.

Com o passar do tempo, a palavra sustentabilidade foi sendo estendida a várias convenções mundiais, até que, na década de oitenta, o Relatório Brundtland ${ }^{4}$ foi o responsável por elaborar o conceito do termo desenvolvimento sustentável, o qual sofreu inúmeras críticas, principalmente por ser entendido como incompatível com o atual modelo capitalista.

Logo, na tentativa de privilegiar as questões ambientais, no ano de 1988, a Constituição Federal Brasileira incluiu o direito a um meio ambiente equilibrado como um dever do Poder Público e da coletividade $^{5}$. Assim, o meio ambiente configurou-se como um bem constitucionalmente protegido, servindo de respaldo para que novas legislações infraconstitucionais também regulamentassem acerca de práticas ambientais equilibradas.

Nesse ponto, o texto constitucional também se valeu do caráter interventivo do sistema penal para tentar tutelar o meio ambiente, reprimir condutas que pudessem violar as normas ambientais, bem como desestimular infratores.

${ }^{4}$ UNITED NATIONS. Our common future. Disponível em: <http://www.undocuments.net/ocf-02.htm>. Acesso em 10 de jun. de 2016.

${ }^{5}$ BRASIL. Constituição $\quad$ Federal. $1988 . \quad$ Disponível em: http://www.planalto.gov.br/ccivil_03/Constituicao/Constituicao.htm. Acesso em 10 de jun. de 2016. 

Sensu em Ciência Jurídica da UNIVALI, Itajaí, v.11, n.2, 2ㅇ quadrimestre de 2016. Disponível em: www.univali.br/direitoepolitica - ISSN 1980-7791.

Desse modo, este trabalho tem o objetivo de investigar se o direito penal, mesmo sendo considerado, na sua própria essência, um sistema complexo e imperfeito, poderia cumprir a função de garantir a tutela do meio ambiente, contribuindo para a concretização da sustentabilidade ambiental.

O problema jurídico formulado para a presente pesquisa questiona se o ser humano pode confiar no direito penal como sendo um efetivo instrumento protetivo, sob um viés ambiental, tendo em vista que alguns estudiosos do sistema penal alegam estar este desprovido de legitimação. Já a hipótese de solução se constrói na possibilidade de demonstrar que o sistema penal possui uma estrutura falha e, consequentemente, inadequada para garantir a sustentabilidade na sua perspectiva ambiental, uma vez que as próprias instituições criminais são taxadas como insustentáveis.

A pesquisa, pois, utiliza o método dedutivo, numa contextualização teórica baseada em pesquisa bibliográfica, a fim de abordar sobre a crise ecológica e sua relação com a sustentabilidade, bem como analisar o meio ambiente como um bem juridicamente protegido e, por fim, estudar sobre a inversão das funções do direito penal (declaradas e reais), a sua deslegitimação e a ausência de pressupostos para enquadrar o sistema penal como um instrumento capaz de tutelar meio ambiente.

\section{A SUSTENTABILIDADE E A CRISE AMBIENTAL}

Chuvas ácidas, aquecimento global, diminuição da camada de ozônio: esses são apenas alguns dos graves problemas ambientais que assombram a humanidade. Ocorre que, ao longo dos anos, o homem foi presenciando uma série de desastres ecológicos, os quais foram 
BALDISSERA, Rafaela. AQUINO. Sérgio Ricardo Fernandes de. A ilusória tutela penal de um meio ambiente sustentável. Revista Eletrônica Direito e Política, Programa de Pós-Graduação Stricto Sensu em Ciência Jurídica da UNIVALI, Itajaí, v.11, n.2, 2ㅇ quadrimestre de 2016. Disponível em: www.univali.br/direitoepolitica - ISSN 1980-7791.

cruciais para que surgissem cidadãos $^{6}$ preocupados em encontrar métodos para impedir que novas catástrofes naturais se materializassem.

Desse modo, com maior compreensão sobre quão negativas eram suas condutas perante o meio ambiente, o ser humano já adquiriu conhecimentos suficientes para entender que, há tempos, vem desestabilizando o ciclo natural do ecossistema terrestre, e que esse desequilíbrio já desencadeou uma verdadeira crise ambiental7.

Assim, diante dos problemas ambientais, a ideia de sustentabilidade surgiu para evitar que um futuro colapso ecológico se firmasse no planeta Terra. Embora a palavra tenha se popularizado há poucas décadas, Bosselmann afirma que os "Conceitos de sustentabilidade não foram inventados no final do século XX, mas cerca de 600 anos antes, quando a Europa continental sofreu uma grave crise ecológica"8.

É pouco conhecido que legislações envolvendo ideais sustentáveis já tenham sido abordadas no século XIV, visto que, em razão da crise

6 Em relação à Cidadania, Aquino destaca que: "A desejada integração humana parece muito distante devido à indiferença endêmica na qual está enraizada na vida cotidiana. Reivindicar algo mais razoável com o apoio (coercitivo) da lei também não parece um caminho que seja próspero porque a imposição normativa esvazia a nossa responsabilidade humana uns com os outros. O exemplo mais claro desse cenário é a descrição legal da Cidadania em terra brasilis. Ser cidadão, hoje, não é uma atitude de simples cumprimento da lei. Esse argumento é pobre e vazio de significado porque os vínculos humanos que se constituem nas múltiplas redes de conversas, atividades e contatos diários não fariam parte daquilo que a Constituição determina como exercício do Direito Político. Reivindica-se um projeto humano cuja convivência esteja além das obrigações determinadas pela imposição normativa do Estado-nação. É necessário uma aproximação transfronteiriça unida pelo nosso vínculo antropológico comum. Esse projeto não é um devaneio abstrato, mas, aos poucos, se torna real, factível no nosso cotidiano, embora precise ser vivenciado e compreendido com maior entusiasmo". AQUINO, Sérgio Ricardo Fernandes de. 0 direito em busca de sua humanidade: diálogos errantes. Curitiba: CRV, 2014, p. 29.

7 BOSSELMANN, Klaus. O princípio da sustentabilidade: transformando direito e governança. Tradução de Phillip Gil França. São Paulo: Revista dos Tribunais, 2015, p. 30/31.

${ }^{8}$ BOSSELMANN, Klaus. O princípio da sustentabilidade, p. 31. 
BALDISSERA, Rafaela. AQUINO. Sérgio Ricardo Fernandes de. A ilusória tutela penal de um meio ambiente sustentável. Revista Eletrônica Direito e Política, Programa de Pós-Graduação Stricto Sensu em Ciência Jurídica da UNIVALI, Itajaí, v.11, n.2, 2ㅇ quadrimestre de 2016. Disponível em: www.univali.br/direitoepolitica - ISSN 1980-7791.

ambiental ocorrida na Europa, "principados e cidades locais tomaram medidas de reflorestamento em larga escala e promulgaram leis fundadas na sustentabilidade. A ideia era não desmatar madeira além do que pudesse crescer novamente e plantar novas árvores para que as gerações futuras fossem beneficiadas" ${ }^{\prime \prime}$.

Percebe-se que a preocupação com a situação ambiental contribuiu para que a ideia básica de sustentabilidade fosse transportada para documentos escritos, como é o caso das legislações. Assim, por meio dessas normas, as pessoas dos séculos passados já tinham sido estimuladas a cumprir regras obrigacionais direcionadas a cuidados com a utilização excessiva e a recomposição dos recursos naturais.

Nos relatos de Bosselmann, o autor assegura que a ideia de sustentabilidade pode ter estado adormecida quando o processo de industrialização surgiu, mas ela nunca deixou de existir. Bosselmann explica que, mesmo paralisada, a percepção de sustentabilidade continuou presente, por muitos anos, na civilização europeia, até que, na década de oitenta, ressurgiu em grandes proporções, revelando-se em todos os cantos do mundo globalizado ${ }^{10}$.

O próprio termo sustentabilidade foi utilizado com frequência durante centenas de anos ${ }^{11}$, e, em 1987, na tentativa de conciliar o meio ambiente com o período econômico, o manifesto, que recebeu o nome

\footnotetext{
${ }^{9}$ O sociólogo Robert Park dedicou-se a estudar "o meio ambiente natural em benefício da própria natureza" e, conforme o autor John Hannigan, Park deve ter verificado que "a intervenção humana, na forma de desenvolvimento urbano e poluição industrial, quebrou artificialmente esta cadeia, causando o 'desequilíbrio biológico'", pois Park acabou por admitir que o comércio destruiu a antiga ordem natural. HANNIGAN, John. Sociologia ambiental. Tradução de Annahid Burnett. Rio de Janeiro: Vozes, 2009, p. 36.

${ }^{10}$ BOSSELMANN, Klaus. O princípio da sustentabilidade, p. 34.

${ }^{11}$ BOSSELMANN, Klaus. O princípio da sustentabilidade, p. 34.
} 
BALDISSERA, Rafaela. AQUINO. Sérgio Ricardo Fernandes de. A ilusória tutela penal de um meio ambiente sustentável. Revista Eletrônica Direito e Política, Programa de Pós-Graduação Stricto Sensu em Ciência Jurídica da UNIVALI, Itajaí, v.11, n.2, 2ㅇ quadrimestre de 2016. Disponível em: www.univali.br/direitoepolitica - ISSN 1980-7791.

de "Nosso Futuro Comum", proferiu o conceito de um novo termo chamado desenvolvimento sustentável ${ }^{12}$.

O referido manifesto ficou conhecido como Relatório Brundtland por ter sido organizado pela Comissão Mundial sobre Ambiente e Desenvolvimento e administrado por Gro Brundtland. Assim, o relatório tentou trazer um diálogo harmônico entre o desenvolvimento e o meio ambiente, assegurando que as futuras gerações possam desfrutar do mesmo padrão de vida que as gerações presentes possuem. Segundo Sen, ficou estabelecido que, em um desenvolvimento sustentável, as necessidades da civilização atual devem ser atendidas sem prejudicar as das civilizações subsequentes ${ }^{13}$.

No entanto, Bosselmann teceu algumas críticas ao Relatório Brundtland afirmando que este poderia ter trazido, primeiramente, o conceito de sustentabilidade para, somente após, determinar o que seria um desenvolvimento sustentável, já que, segundo o autor, distintos são os sentidos desses dois termos ${ }^{14}$.

Para Aquino, "A Sustentabilidade tem, sim, diferenças conceituais acerca do Desenvolvimento Sustentável. É, ainda, um princípio jurídico que não pode ser esquecido, nem ignorado e tampouco confundido com seu 'primo rico' chamado Desenvolvimento Sustentável"15.

12 SEN, Amartya. Por que é necessário preservar a coruja-pintada. FOLHA DE SÃO PAULO. São Paulo, 14 de março de 2014. Disponível em: http://www1.folha.uol.com.br/folha/ciencia/ult306u11316.shtml. Acesso em 15 de jun. de 2016, p. 1.

13 SEN, Amartya. FOLHA DE SÃO PAULO. p. 1

14 BOSSELMANN, Klaus. O princípio da sustentabilidade, p. 45.

15 AQUINO, Sérgio Ricardo Fernandes. Empório do direito. Princípio jurídico esquecido da sustentabilidade. Disponível em: <http://emporiododireito.com.br/o-principio-juridico-esquecido-dasustentabilidade-por-sergio-ricardo-fernandes-de-aquino/>. Acesso em: 17 jun. 2016 , p. 1. 
BALDISSERA, Rafaela. AQUINO. Sérgio Ricardo Fernandes de. A ilusória tutela penal de um meio ambiente sustentável. Revista Eletrônica Direito e Política, Programa de Pós-Graduação Stricto Sensu em Ciência Jurídica da UNIVALI, Itajaí, v.11, n.2, 2ㅇ quadrimestre de 2016. Disponível em: www.univali.br/direitoepolitica - ISSN 1980-7791.

Nesse sentido, Budó alerta que o conceito de desenvolvimento sustentável vem "sendo submetido a numerosas críticas, a maior parte delas em razão da tensão entre os termos 'desenvolvimento' e 'sustentável', para alguns totalmente inconciliáveis no sistema capitalista"16.

Percebe-se, então, que distintos autores já encontraram incoerências sobre o conceito de desenvolvimento sustentável, e alguns salientam que a própria expressão é contraditória. Nesse passo, torna-se complexo compreender como um desenvolvimento poderia ser transformado em algo efetivamente sustentável se o regime capitalista desenvolve hábitos voltados ao acúmulo de capital e, por conseguinte, acaba conduzindo algumas ações humanas para o caminho da devastação ambiental.

Corroborando com essas ponderações, Leff explica que a expansão do sistema capitalista, impulsionada pela racionalidade econômica, encontra-se relacionada com os problemas ambientais ${ }^{17}$. Para o autor:

A problemática ambiental não é ideologicamente neutra
nem é alheia a interesses econômicos e sociais. Sua
gênese dá-se num processo histórico dominado pela
expansão do modo de produção capitalista, pelos
padrões tecnológicos gerados por uma racionalidade
econômica guiada pelo propósito de maximizar os lucros
e os excedentes econômicos a curto prazo ${ }^{18}$.

Dessa forma, entende-se que a acentuada extração dos meios naturais está apoiada no pensamento antropocêntrico, o qual eleva o ser

16 BUDÓ, Marília de Nardin. Criminologia e dano moral: a efetivação da sustentabilidade de para além do direito penal. In: TRINDADE, André Karam; ESPÍNDOLA, Ângela Araújo da Silveira; BOFF, Salete Oro (Orgs.). Direito, Democracia e Sustentabilidade: anuário do Programa de Pós-Graduação Stricto Sensu em Direito, Democracia e Sustentabilidade. Passo Fundo: IMED Editora, 2014, p. $373-406$, p. 379.

17 LEFF, Enrique. Epistemologia ambiental. Tradução de Sandra Valenzuela. São Paulo: Cortez, 2010, p. 64.

${ }^{18}$ LEFF, Enrique. Epistemologia ambiental, p. 64. 
BALDISSERA, Rafaela. AQUINO. Sérgio Ricardo Fernandes de. A ilusória tutela penal de um meio ambiente sustentável. Revista Eletrônica Direito e Política, Programa de Pós-Graduação Stricto Sensu em Ciência Jurídica da UNIVALI, Itajaí, v.11, n.2, 2ㅇ quadrimestre de 2016. Disponível em: www.univali.br/direitoepolitica - ISSN 1980-7791.

humano para uma posição central no ciclo ecológico. Conquanto, a categoria utilitarista antropocêntrica, parece traduzir melhor a forma como o meio ambiente está sendo 'coisificado', pois destina-se a comercializar todos os recursos naturais que são retirados da Natureza, valorando a utilidade econômica da Terra ${ }^{19}$.

Segundo Gudynas, a visão antropocêntrica (utilitarista) sobressaiu-se na maioria dos documentos elaborados em conferências com viés ecológico nas décadas de setenta e oitenta, até porque, nessa época, o homem era visto como um ser privilegiado no ecossistema, ou seja, quem realmente importava era o ser humano, e o meio ambiente deveria estar equilibrado apenas para servi-Io20.

$\mathrm{Na}$ visão de Gudynas, nas últimas décadas, muitos eventos, conferências e documentos, em prol do meio ambiente, foram realizados, no entanto a maioria deles não aprofundou a questão da ética ambiental. $\mathrm{O}$ autor citou, inclusive, que o Relatório Brundtland criou o conceito de desenvolvimento sustentável, mas também deixou de trilhar um caminho ambientalmente ético ${ }^{21}$.

Importante ressaltar que Gudynas é um defensor dos direitos da Natureza e dialoga sobre a preocupante situação ambiental, identificando que ela foi constituída devido a vários fatores, contudo ressalta a superexploração dos meios naturais como um agravante para esse cenário 22.

Assim, os interesses produtivos, reforçados pelo regime capitalista, buscam atribuir um preço à Natureza e, consequentemente,

19 GUDYNAS, Eduardo. Derechos de la naturaleza: ética biocéntrica y políticas ambientales. Lima: CLAES, 2014, p. 31.

20 GUDYNAS, Eduardo. Derechos de la naturaleza, p. 34.

${ }^{21}$ GUDYNAS, Eduardo. Derechos de la naturaleza, p. 34/35.

22 GUDYNAS, Eduardo. Derechos de la naturaleza, p. 27/28. 
BALDISSERA, Rafaela. AQUINO. Sérgio Ricardo Fernandes de. A ilusória tutela penal de um meio ambiente sustentável. Revista Eletrônica Direito e Política, Programa de Pós-Graduação Stricto Sensu em Ciência Jurídica da UNIVALI, Itajaí, v.11, n.2, 2ㅇ quadrimestre de 2016. Disponível em: www.univali.br/direitoepolitica - ISSN 1980-7791.

consideram-na um bem material. Portanto, verifica-se que é demasiadamente complexo falar em um equilíbrio entre as dimensões ambientais e econômicas, até porque os costumes, voltados à dominação dos meios naturais, já estão enraizados na sociedade há muitos anos, conforme precisou Gudynas, desde o Renascimento ${ }^{23}$.

Nesse sentido, Latouche explica que os padrões econômicos são incompatíveis com a finitude da biosfera, demonstrando que a acentuada extração dos meios naturais, os desmatamentos, as queimadas, o alto grau de poluição e a volumosa quantidade de lixo lançada ao meio ambiente trazem maior instabilidade à concretização de um equilíbrio ambiental a longo prazo. Para Latouche:

Nosso crescimento econômico excessivo choca-se com os limites da finitude da biosfera. A capacidade de regeneração da Terra já não consegue acompanhar a demanda: o homem transforma os recursos em resíduos mais rápidos do que a natureza consegue transformar esses resíduos em novos recursos ${ }^{24}$.

Diante disso, percebe-se que a expressão desenvolvimento sustentável se assemelha mais aos fundamentos antropocêntricos de raiz utilitarista, voltados aos interesses econômicos do homem, do que aos ideais éticos ambientais que constituem propriamente a sustentabilidade.

Contudo, a grave crise ambiental demanda um esforço comum no sentido de buscar alternativas para que a visão antropocêntrica seja transformada em ecocêntrica, oportunizando uma equilibrada convivência entre elementos naturais e os interesses da espécie humana.

23 GUDYNAS, Eduardo. Derechos de la naturaleza, p. 28.

24 LATOUCHE, Serge. Pequeno tratado do decrescimento sereno. Tradução de Cláudia Berliner. São Paulo: Martins Fontes, 2009, p. 27. 
BALDISSERA, Rafaela. AQUINO. Sérgio Ricardo Fernandes de. A ilusória tutela penal de um meio ambiente sustentável. Revista Eletrônica Direito e Política, Programa de Pós-Graduação Stricto Sensu em Ciência Jurídica da UNIVALI, Itajaí, v.11, n.2, 2ㅇ quadrimestre de 2016. Disponível em: www.univali.br/direitoepolitica - ISSN 1980-7791.

Portanto, se faz necessário evitar que novas condutas nocivas ao meio ambiente sejam efetivadas, pois os devastadores ambientais devem ser desestimulados a praticar novos danos.

Dessa forma, a fim de direcionar comportamentos coletivos que auxiliem na preservação ambiental, o ser humano utilizou-se do poder intervencionista de normatizações constitucionais e infraconstitucionais, para induzir práticas ambientais equilibradas, compor regras educativas, assegurar a proteção de meios naturais, pontuar condutas reprováveis, delimitar penas, qualificando, assim, o meio ambiente como um bem que deve ser juridicamente protegido.

\section{MEIO AMBIENTE: UM BEM JURIDICAMENTE PROTEGIDO}

O direito a um meio ambiente equilibrado foi elevado a uma categoria constitucional e, assim, foram asseguradas regras e deveres voltados à preservação ambiental. Desse modo, o reconhecimento jurídico do desenvolvimento sustentável foi preconizado, pelas normas brasileiras, no artigo 225 da Constituição Federal de 1988, o qual ensina ser preciso conservar o meio ambiente para que as futuras gerações também possam usufruir de uma boa qualidade de vida. Tal artigo determina que:

Todos têm direito ao meio ambiente ecologicamente equilibrado, bem de uso comum do povo e essencial à sadia qualidade de vida, impondo-se ao Poder Público e à coletividade o dever de defendê-lo e preservá-lo para as presente e futuras gerações $\S 1^{\circ}$ Para assegurar a efetividade desse direito, incumbe ao Poder Público: I preservar e restaurar os processos ecológicos essenciais e prover o manejo ecológico das espécies e ecossistemas; II - preservar a diversidade e a integridade do patrimônio genético do País e fiscalizar as entidades dedicadas à pesquisa e manipulação de material genético; III - definir, em todas as unidades da Federação, espaços territoriais e seus componentes a serem especialmente protegidos, sendo a alteração e a 

Sensu em Ciência Jurídica da UNIVALI, Itajaí, v.11, n.2, 2ㅇ quadrimestre de 2016. Disponível em: www.univali.br/direitoepolitica - ISSN 1980-7791.

\begin{abstract}
supressão permitidas somente através de lei, vedada qualquer utilização que comprometa a integridade dos atributos que justifiquem sua proteção; IV - exigir, na forma da lei, para instalação de obra ou atividade potencialmente causadora de significativa degradação do meio ambiente, estudo prévio de impacto ambiental, a que se dará publicidade; V - controlar a produção, a comercialização e o emprego de técnicas, métodos e substâncias que comportem risco para a vida, a qualidade de vida e o meio ambiente; VI - promover a educação ambiental em todos os níveis de ensino e a conscientização pública para a preservação do meio ambiente; VII - proteger a fauna e a flora, vedadas, na forma da lei, as práticas que coloquem em risco sua função ecológica, provoquem a extinção de espécies ou submetam os animais a crueldade ${ }^{25}$.
\end{abstract}

Essas determinações constitucionais demonstram que o ordenamento jurídico brasileiro, há anos, já se preocupava em orientar comportamentos inibidores de ações atentatórias ao meio ambiente. Ocorre que, mesmo antes da vigência do artigo 225, algumas leis com viés ambiental (como é o caso da Lei de Política Nacional do Meio Ambiente, n. 6938, de 1981) já tinham sido criadas, mas somente após a promulgação da Constituição Federal, contendo em seu capítulo VI o título 'Do Meio Ambiente', é que legislações ambientais, mais específicas, começaram a surgir no sistema jurídico.

Entre as leis posteriores ao ano de 1988, destacam-se: a Lei 7.735/1989, a qual cria o Instituto Brasileiro do Meio Ambiente e dos Recursos Naturais Renováveis; a Lei 7.797/1989, responsável pelo Fundo Nacional de Meio Ambiente; a Lei 9.605/1998, que prevê os Crimes Ambientais; a Lei 9.795/1999, sobre Educação Ambiental e Política Nacional de Educação Ambiental; a Lei 9.985/2000, que regulamenta o Sistema Nacional de Unidades de Conservação da

\footnotetext{
${ }^{25}$ BRASIL. Constituição Federal. 1988. Disponível em: http://www.planalto.gov.br/ccivil_03/Constituicao/Constituicao.htm. Acesso em 10 de jun. de 2016.
} 
BALDISSERA, Rafaela. AQUINO. Sérgio Ricardo Fernandes de. A ilusória tutela penal de um meio ambiente sustentável. Revista Eletrônica Direito e Política, Programa de Pós-Graduação Stricto Sensu em Ciência Jurídica da UNIVALI, Itajaí, v.11, n.2, 2ำ quadrimestre de 2016. Disponível em: www.univali.br/direitoepolitica - ISSN 1980-7791.

Natureza; a Lei 11.105/2005, chamada Lei de Biossegurança; a Lei 11.284/2006, referindo-se à gestão de Florestas Públicas; e também deve ser citada a recente Lei $12.651 / 2012$, que institui o novo Código Florestal.

Ainda, interessante ressaltar que a vasta legislação ambiental não está toda inclusa nesse rol $^{26}$, pois há outras leis e regulamentações esparsas, em favor do meio ambiente, que também fazem parte do diploma legal.

Nesse sentido, seguindo os mandamentos da Lei Maior, percebe-se que diversos ramos do Direito vincularam seus institutos jurídicos, a fim de reforçar a proteção ao meio ambiente. Assim, não passou despercebido o respaldo que a Constituição Federal conferiu à esfera penal, oportunizando que criassem medidas coercitivas aos transgressores ambientais.

Dessa forma, o parágrafo $3^{\circ}$ do artigo 225 pondera que "as condutas e atividades consideradas lesivas ao meio ambiente sujeitarão os infratores, pessoas físicas ou jurídicas, a sanções penais e administrativas, independentemente da obrigação de reparar os danos causados"27.

Observa-se que a referida citação constitucional valeu-se do caráter interventivo do sistema penal para contribuir com a minimização das condutas causadoras de danos ambientais. Assim, a tutela penal vem

26 AGUIRRE, João Ricardo Brandão; TÁVORA, Nestor. Leis contidas no Vade Mecum. Rio de Janeiro: Forense: São Paulo: Método, 2014, p. 58.

${ }^{27}$ BRASIL. Constituição $\quad$ Federal. 1988. Disponível em: http://www.planalto.gov.br/ccivil_03/Constituicao/Constituicao.htm. Acesso em 10 de jun. de 2016. 
BALDISSERA, Rafaela. AQUINO. Sérgio Ricardo Fernandes de. A ilusória tutela penal de um meio ambiente sustentável. Revista Eletrônica Direito e Política, Programa de Pós-Graduação Stricto Sensu em Ciência Jurídica da UNIVALI, Itajaí, v.11, n.2, 2ㅇ quadrimestre de 2016. Disponível em: www.univali.br/direitoepolitica - ISSN 1980-7791.

sendo alargada, e suas funções passaram a proteger também bens supraindividuais, como é o caso do meio ambiente 28.

Assinalando positivamente para a consagração de tipos penais direcionados à proteção ambiental, Palma refere-se ao direito penal como "um importante meio de coação de condutas que de alguma maneira venham a ofender o meio ambiente, objetivando, com isso, mantê-lo equilibrado e adequado para que o homem possa se autodeterminar e se desenvolver"29.

Nessa linha de entendimento, observa-se que o autor acredita na viabilidade da tutela penal do meio ambiente, porque, possivelmente, considera válida a função declarada que o direito penal anuncia: "preservação do bem comum"30. Por outro lado, se a função real passasse a ser valorizada, haveria a compreensão de que as mensagens de repreensão e ameaça, trazidas pelo sistema penal, são, na verdade, uma forma de esconder a falta de controle e de legitimidade desse instrumento.

Assim, em sua função declarada, o direito penal propõe ser a melhor alternativa para desestimular condutas reprováveis, intervir nos padrões comportamentais da sociedade, preservar os bens jurídicos e

\footnotetext{
${ }^{28}$ BUDÓ, Marília de Nardin. Direito, Democracia e Sustentabilidade: Anuário do Programa de Pós-Graduação Stricto Sensu em Direito, Democracia e Sustentabilidade. p. 385.

29 PALMA, Fernando Oliva. Tutela penal do meio ambiente: a importância dos tipos penais de perigo na difícil tarefa de evitar o dano ambiental. Revista Magister de Direito Ambiental e Urbanístico. Núm. 39, dez-jan de 2012, p. 33 a 45. Disponível em: $\quad<$ http://www.santossilveiro.com.br/wp-content/uploads/2012/03/Artigo-Atutela-penal-do-meio-ambiente-Fernando-Palma.pdf>. Acesso em 20 de jun. de 2016.

30 Paralelamente Fragoso destaca que "a justificação da pena liga-se à função do Direito Penal, que é instrumento da política social do Estado. O Estado, como tutor e mantenedor da ordem jurídica, serve-se do Direito Penal, ou seja, da pena e das medidas de segurança, como meios destinados à consecução e à preservação do bem comum (controle social)". FRAGOSO, Heleno Cláudio. Lições de direito penal: parte geral. Rio de Janeiro: Forense, 2004, p. 04.
} 
BALDISSERA, Rafaela. AQUINO. Sérgio Ricardo Fernandes de. A ilusória tutela penal de um meio ambiente sustentável. Revista Eletrônica Direito e Política, Programa de Pós-Graduação Stricto Sensu em Ciência Jurídica da UNIVALI, Itajaí, v.11, n.2, 2ㅇ quadrimestre de 2016. Disponível em: www.univali.br/direitoepolitica - ISSN 1980-7791.

colaborar com o controle social; entretanto, a operacionalidade real do sistema penal demonstra que este já pode ser considerado um sistema deslegitimado, até mesmo para abrigar a esfera ambiental.

\section{A DESLEGITIMAÇÃO DO DIREITO PENAL FRENTE À TUTELA DO MEIO AMBIENTE}

Os discursos declarados pelo direito penal tentam validar esse sistema como o principal reparador e inibidor de danos. Todavia, na prática, as promessas de proteção permanecem sendo apenas promessas, isto é, nenhuma ação é efetivamente realizada para que se tornem reais.

Observa-se que as próprias funções declaradas pelo direito penal não correspondem à realidade, pois não são cumpridas. E uma situação diversa ocorre com as funções reais, visto que estas têm uma realidade ocultada, ou seja, há o cumprimento de funções que o sistema não declarou ${ }^{31}$.

Essa inversão de funções é denominada, por Andrade, "eficácia invertida", e, em explicações sobre a composição do "retrato das deslegitimações" do sistema penal, a autora assegura que "a marca do sistema penal é a 'eficácia invertida', ou seja, a contradição entre funções declaradas ou promessas que não cumpre e funções reais que cumpre sem declarar"32.

Interessante ressaltar que, em meio às críticas teóricas e práticas, o próprio sistema penal tenta se autolegitimar de duas formas: por meio da legalidade, a qual se centra no garantismo; e a outra é feita pela

\footnotetext{
${ }^{31}$ ANDRADE, Vera Regina Pereira. Minimalismos, abolucionismos e eficienticismo: a crise do sistema penal entre a deslegitimação e a expansão. Revista Sequência, $n$. 52, julho de 2006, p. 163-182, p. 170.

32 ANDRADE, Vera Regina Pereira. Revista Sequência, p. 170.
} 
BALDISSERA, Rafaela. AQUINO. Sérgio Ricardo Fernandes de. A ilusória tutela penal de um meio ambiente sustentável. Revista Eletrônica Direito e Política, Programa de Pós-Graduação Stricto Sensu em Ciência Jurídica da UNIVALI, Itajaí, v.11, n.2, 2ㅇ quadrimestre de 2016. Disponível em: www.univali.br/direitoepolitica - ISSN 1980-7791.

utilidade, ou seja, procura destacar as finalidades da pena. Assim, para Andrade:

[...] o poder de punir e o sistema penal em que se institucionaliza é marcado por uma dupla via legitimadora. Por um lado, por uma justificação e legitimação pela legalidade que se conecta com o seu enquadramento na programação normativa; por outro lado, por uma justificação e legitimação utilitarista que se conecta com a definição dos fins (funções declaradas) perseguidos pela pena ${ }^{33}$.

Sob os olhos de Karam, a maioria das pessoas não percebe, mas, atualmente, um novo e diferente modelo de autoritarismo está sendo exercido por meio do sistema penal. Ocorre que a sociedade assinala positivamente ao aumento do poder punitivo, pois, com ingenuidade, compreende que esses avanços auxiliam no controle social e, por consequência, na segurança pública. Contudo, essas funções repressivas do sistema penal enfraquecem o Estado Democrático de Direito, bem como agravam os problemas sociais, o perigo de lesões, a seletividade e a violência ${ }^{34}$.

Dessa maneira, uma imagem distorcida do sistema penal está sendo internalizada na sociedade. Os usuários do sistema são diariamente enganados, já que, na tentativa de autolegitimar-se ${ }^{35}$, o direito penal acaba por declarar o que não pode cumprir ou, na realidade, o que não quer cumprir. Entretanto, para que a população acredite na sua

\footnotetext{
${ }^{33}$ ANDRADE, Vera Regina Pereira. A ilusão de segurança jurídica: do controle da violência à violência do controle. Porto Alegre: Livraria do Advogado, 2003, p. 177. 34 KARAM, Maria Lúcia. Recuperar o desejo da liberdade e conter o poder punitivo. Rio de Janeiro: Lumen Juris, 2009, p. 13/14.

35 Importante, ainda, dialogar sobre a diferença entre legitimidade e legitimação, segundo Andrade "Por legitimidade entendemos uma qualidade que se pode predicar ao sistema pela relação de congruência entre programação (normativa e teleológica) e operacionalização. Por legitimação entendemos o processo mediante o qual se atribui esta qualidade ao sistema." ANDRADE, Vera Regina Pereira. A ilusão de segurança jurídica, p. 181.
} 
BALDISSERA, Rafaela. AQUINO. Sérgio Ricardo Fernandes de. A ilusória tutela penal de um meio ambiente sustentável. Revista Eletrônica Direito e Política, Programa de Pós-Graduação Stricto Sensu em Ciência Jurídica da UNIVALI, Itajaí, v.11, n.2, 2ㅇ quadrimestre de 2016. Disponível em: www.univali.br/direitoepolitica - ISSN 1980-7791.

aparência protetiva, necessita estar sempre reiterando seus discursos fictícios.

Diante disso, a fim de buscar a confiança da sociedade, as manifestações públicas do sistema penal geralmente carregam "uma linguagem impregnada por forte carga emocional, uma linguagem assustadora, demonizadora, que funciona como um instrumento particularmente importante para o exercício do poder punitivo"36.

Segundo Budó, na verdade, o direito penal não tem a pretensão de tutelar os bens jurídicos, apenas traz uma ilusória perspectiva de que cumpre essa função. Assim, o direito penal encontra-se legitimado apenas de uma forma simbólica, visto que procura passar uma ideia de confiabilidade para a população ${ }^{37}$.

Em suma, confiar no direito penal como um sistema seguro e igualitário é o mesmo que viver de aparências, porquanto "o sistema penal gera situações muito mais graves e dolorosas do que os conflitos qualificados como crimes, que, enganosamente, anuncia poder resolver"38. E, ainda, segundo Baratta, "o direito penal é um instrumento precípuo de produção e de reprodução de relações de desigualdade" 39 .

A partir dessas ponderações, entende-se que as condutas por trás do sistema penal são contrárias aos princípios democráticos. Dessa maneira, anunciando discursos dissimulados, voltados à proteção do

\footnotetext{
36 KARAM, Maria Lúcia. Recuperar o desejo da liberdade e conter o poder punitivo, p. 19.

37 BUDÓ, Marília de Nardin. Direito, Democracia e Sustentabilidade: Anuário do Programa de Pós-Graduação Stricto Sensu em Direito, Democracia e Sustentabilidade, p. 392.

38 KARAM, Maria Lúcia. Recuperar o desejo da liberdade e conter o poder punitivo, p. 14.

${ }^{39}$ BARATTA, Alessandro. Criminologia crítica e crítica do direito penal. Tradução de Juarez Cirino dos Santos Rio de Janeiro: Revan/ICC, 2002, p. 207.
} 
BALDISSERA, Rafaela. AQUINO. Sérgio Ricardo Fernandes de. A ilusória tutela penal de um meio ambiente sustentável. Revista Eletrônica Direito e Política, Programa de Pós-Graduação Stricto Sensu em Ciência Jurídica da UNIVALI, Itajaí, v.11, n.2, 2ㅇ quadrimestre de 2016. Disponível em: www.univali.br/direitoepolitica - ISSN 1980-7791.

bem comum, este sistema acaba por divulgar a falsa ideia de fomentar a igualdade, quando, na verdade, é caracterizado por criar e reproduzir desigualdades ${ }^{40}$.

Percebe-se, então, que as funções reais do sistema penal opõem-se à veste protetora que legitima as suas instituições e, por esse motivo, acabam sendo omitidas. Já as funções declaradas, como proteção de bens jurídicos, segurança jurídica e prevenção de crimes, são divulgadas, mas descartadas, pois necessitam permanecer no quadro das promessas para que o sistema consiga cumprir seu ciclo de ilusões ${ }^{41}$.

Logo, como o meio ambiente é considerado um bem que deve ser juridicamente protegido, e essa função protetiva também foi estendida para a esfera penal, entende-se que o direito penal, sendo um sistema reprodutor de conflitos e desigualdades, não é um meio efetivo para auxiliar na preservação ambiental, nem mesmo para promover a sustentabilidade ${ }^{42}$.

Portanto, entende-se que as suas funções declaradas iludem os cidadãos, fazendo com que as funções reais passem despercebidas. A partir dessas análises, o direito penal pode ser considerado o responsável por desestruturar os ideais democráticos e corromper a própria estrutura social.

Na visão de Budó, "mais do que proteger o meio ambiente, o sistema penal tem uma eficácia inversa: a de violá-lo, a começar pela

\footnotetext{
${ }^{40}$ BARATTA, Alessandro. Criminologia crítica e crítica do direito penal, p. 207.

${ }^{41}$ ANDRADE, Vera Regina Pereira. Revista Sequência, p. 171.

42 BUDÓ, Marília de Nardin. Direito, Democracia e Sustentabilidade: Anuário do Programa de Pós-Graduação Stricto Sensu em Direito, Democracia e Sustentabilidade, p. 397.
} 
BALDISSERA, Rafaela. AQUINO. Sérgio Ricardo Fernandes de. A ilusória tutela penal de um meio ambiente sustentável. Revista Eletrônica Direito e Política, Programa de Pós-Graduação Stricto Sensu em Ciência Jurídica da UNIVALI, Itajaí, v.11, n.2, 2ㅇ quadrimestre de 2016. Disponível em: www.univali.br/direitoepolitica - ISSN 1980-7791.

vulneração da vida humana"43. Assim, as questões ambientais devem ser afastadas do caráter negativo das funções reais do direito penal, pois a proteção jurídica do meio ambiente não pode resultar na reprodução de lesões a bens jurídicos individuais.

Nessa contextualização, Budó salienta que os danos trazidos pelo sistema penal agravam os conflitos sociais, promovendo, ainda mais, a criminalidade por meio de condutas punitivas e seletivas. Conclui-se, assim, que o próprio sistema penal não se sustenta, pois é revestido de parcialidade, priorizando práticas que privilegiem o sistema dos mais poderosos ${ }^{44}$.

Dessa forma, por tais razões, o direito penal não corresponde às expectativas que se buscam encontrar em uma adequada estrutura de tutela para o meio ambiente, bem como para a promoção da sustentabilidade. Nesse sentido, Budó explica que:

[...] partindo-se do princípio de que a sustentabilidade somente poderá ser alcançada quando for questionada a superada a estrutura de poder global que determina a reprodução social das desigualdades, e, junto com ela, a degradação do planeta, é evidente que o sistema penal, enquanto órgão reprodutor das desigualdades não pode ser visto como mecanismo idôneo a tal função ${ }^{45}$.

Portanto, a deslegitimação do sistema penal parece ser óbvia, contudo, diante do apelo emocional que este exterioriza, permanece a dificuldade em convencer os membros da sociedade que o poder criminalizador não tem condições de assegurar a tutela dos bens

\footnotetext{
${ }^{43}$ BUDÓ, Marília de Nardin. Direito, Democracia e Sustentabilidade: Anuário do Programa de Pós-Graduação Stricto Sensu em Direito, Democracia e Sustentabilidade, p. 398/399.

${ }^{44}$ BUDÓ, Marília de Nardin. Direito, Democracia e Sustentabilidade: Anuário do Programa de Pós-Graduação Stricto Sensu em Direito, Democracia e Sustentabilidade, p. 396/398.

45 BUDÓ, Marília de Nardin. Direito, Democracia e Sustentabilidade: Anuário do Programa de Pós-Graduação Stricto Sensu em Direito, Democracia e Sustentabilidade, p. 396/398.
} 
BALDISSERA, Rafaela. AQUINO. Sérgio Ricardo Fernandes de. A ilusória tutela penal de um meio ambiente sustentável. Revista Eletrônica Direito e Política, Programa de Pós-Graduação Stricto Sensu em Ciência Jurídica da UNIVALI, Itajaí, v.11, n.2, 2ำ quadrimestre de 2016. Disponível em: www.univali.br/direitoepolitica - ISSN 1980-7791.

jurídicos que foram colocados sob a sua responsabilidade. Sendo assim, o ser humano não pode confiar sua própria existência, bem como dos demais seres vivos e de todo o ecossistema, em um instrumento falho, ilusório e corrompido, como o direito penal tem revelado ser.

\section{CONSIDERAÇÕES FINAIS}

Neste estudo, o qual tratou sobre a ilusória tutela penal de um meio ambiente sustentável, constatou-se que as consequências da irresponsabilidade humana perante o mesmo já ultrapassaram os níveis de previsibilidade estimados pelo homem, pois a crise ambiental trouxe consigo marcas de retaliação, demonstrando que a dominação forçada da natureza tem um custo.

Diante desse cenário, visando a impedir que a crise ecológica se estendesse, o ser humano passou a realizar movimentos ambientalistas e conferências mundiais, contudo a raiz antropocêntrica utilitarista seguiu como uma legítima integrante dos debates em prol ao meio ambiente, fazendo com que a verdadeira questão ética ambiental ficasse excluída.

Observou-se, ainda, que a Constituição Federal inaugurou no seu texto de 1988 o direito a um meio ambiente equilibrado, assegurando normas de preservação ambiental e atribuindo responsabilidades à atual geração, a fim de que conservasse o meio ambiente para as gerações futuras. Diante disso, também foram criadas normatizações infraconstitucionais com o intuito de resguardar o meio ambiente e torná-lo um bem juridicamente protegido.

Nesse sentido, seguindo os mandamentos da Lei Maior, a legislação ambiental foi ampliada em várias áreas do direito. Na esfera penal, a 
BALDISSERA, Rafaela. AQUINO. Sérgio Ricardo Fernandes de. A ilusória tutela penal de um meio ambiente sustentável. Revista Eletrônica Direito e Política, Programa de Pós-Graduação Stricto Sensu em Ciência Jurídica da UNIVALI, Itajaí, v.11, n.2, 2ำ quadrimestre de 2016. Disponível em: www.univali.br/direitoepolitica - ISSN 1980-7791.

função protetiva foi sendo estendida também aos bens supraindividuais, como o meio ambiente, e, quanto a isso, a Constituição Federal não deixou dúvidas, pois oportunizou, no próprio texto constitucional, a criação de medidas coercitivas aos transgressores ambientais.

Contudo, apesar de o direito penal declarar ser quem promove a defesa social, encontra-se deslegitimado para tratar questões criminais e, também, ambientais. Sendo assim, restou confirmada a hipótese sugerida no presente artigo, a fim de demonstrar que o direito penal não é um sistema adequado para tutelar do meio ambiente, muito menos para promover a sustentabilidade ambiental.

Dessa maneira, os cidadãos não podem confiar nas falsas promessas do sistema penal, dado que uma imagem distorcida desse sistema está sendo internalizada na sociedade, pois a população acredita nos discursos fictícios, os quais o poder criminalizador utiliza para autolegitimar-se, sendo que, por consequência, o Estado Democrático de Direito torna-se, cada vez mais, enfraquecido.

Assim, considerando que as finalidades reais do sistema penal são contrárias aos ideais sustentáveis, a tutela ambiental parece ser inconciliável com o sistema penal, visto que o meio ambiente precisa ser protegido por sistemas eficazes, confiáveis e harmônicos aos propósitos da sustentabilidade ambiental.

O ser humano, pois, necessita estruturar uma forma apropriada de proteger o meio ambiente, sem precisar confiar em um sistema deslegitimado como é o direito penal. Assim, a promoção de políticas públicas, bem como o auxílio de entidades e organizações que estejam engajadas nas causas ambientais, podem orientar as condutas sociais, 
BALDISSERA, Rafaela. AQUINO. Sérgio Ricardo Fernandes de. A ilusória tutela penal de um meio ambiente sustentável. Revista Eletrônica Direito e Política, Programa de Pós-Graduação Stricto Sensu em Ciência Jurídica da UNIVALI, Itajaí, v.11, n.2, 2ㅇ quadrimestre de 2016. Disponível em: www.univali.br/direitoepolitica - ISSN 1980-7791.

demonstrando que a coletividade consegue preservar o meio ambiente sem reproduzir desigualdades.

\section{REFERÊNCIAS DAS FONTES CITADAS}

AGUIRRE, João Ricardo Brandão; TÁVORA, Nestor. Leis contidas no Vade Mecum. Rio de Janeiro: Forense: São Paulo: Método, 2014.

ANDRADE, Vera Regina Pereira. A ilusão de segurança jurídica: do controle da violência à violência do controle. Porto Alegre: Livraria do Advogado, 2003.

ANDRADE, Vera Regina Pereira. Minimalismos, abolucionismos e eficienticismo: a crise do sistema penal entre a deslegitimação e a expansão. Revista Sequência, n. 52, julho de 2006.

AQUINO, Sérgio Ricardo Fernandes de. 0 direito em busca de sua humanidade: diálogos errantes. Curitiba: CRV, 2014.

AQUINO, Sérgio Ricardo Fernandes. Empório do direito. Princípio jurídico esquecido da sustentabilidade. Disponível em: <http://emporiododireito.com.br/o-principio-juridico-esquecido-dasustentabilidade-por-sergio-ricardo-fernandes-de-aquino/>. Acesso em: 17 jun. 2016.

BARATTA, Alessandro. Criminologia crítica e crítica do direito penal. Tradução de Juarez Cirino dos Santos. Rio de Janeiro: Revan/ICC, 2002.

BOSSELMANN, Klaus. 0 princípio da sustentabilidade: transformando direito e governança. Tradução de Phillip Gil França. São Paulo: Revista dos Tribunais, 2015.

BRASIL. Constituição Federal. 1988. Disponível em: http://www.planalto.gov.br/ccivil_03/Constituicao/Constituicao.htm. Acesso em 10 de jun. de 2016.

BUDÓ, Marília de Nardin. Criminologia e dano moral: a efetivação da sustentabilidade de para além do direito penal. In: TRINDADE, André Karam; ESPÍNDOLA, Ângela Araújo da Silveira; BOFF, Salete Oro (Orgs.). Direito, Democracia e Sustentabilidade: anuário do Programa de Pós-Graduação Stricto Sensu em Direito, Democracia e Sustentabilidade. Passo Fundo: IMED Editora, 2014.

FRAGOSO, Heleno Cláudio. Lições de direito penal: parte geral. Rio de Janeiro: Forense, 2004. 
GUDYNAS, Eduardo. Derechos de la naturaleza: ética biocéntrica y políticas ambientales. Lima: CLAES, 2014.

HANNIGAN, John. Sociologia ambiental. Tradução de Annahid Burnett. Rio de Janeiro: Vozes, 2009.

KARAM, Maria Lúcia. Recuperar o desejo da liberdade e conter o poder punitivo. Rio de Janeiro: Lumen Juris, 2009.

LATOUCHE, Serge. Pequeno tratado do decrescimento sereno. Tradução de Cláudia Berliner. São Paulo: Martins Fontes, 2009.

LEFF, Enrique. Epistemologia ambiental. Tradução de Sandra Valenzuela. São Paulo: Cortez, 2010.

PALMA, Fernando Oliva. Tutela penal do meio ambiente: a importância dos tipos penais de perigo na difícil tarefa de evitar o dano ambiental. Revista Magister de Direito Ambiental e Urbanístico, n. 39, dezjan. 2012, p. 33-45. Disponível em: <http://www.santossilveiro.com.br/wpcontent/uploads/2012/03/Artigo-A-tutela-penal-do-meio-ambienteFernando-Palma.pdf>. Acesso em: 20 jun. 2016.

SEN, Amartya. Por que é necessário preservar a coruja-pintada. FOLHA DE SÃo PAULO. São Paulo, 14 de março de 2014. Disponível em: http://www1.folha.uol.com.br/folha/ciencia/ult306u11316.shtml. Acesso em 15 de jun. de 2016.

UNITED NATIONS. Our common future. Disponível em: <http://www.un-documents.net/ocf-02.htm>. Acesso em 10 de jun. de 2016.

Submetido em: julho de 2016

Aprovado em: julho de 2016. 